\title{
Structural Racism and COVID-19 in the USA: a County-Level Empirical Analysis
}

\author{
Shin Bin Tan ${ }^{1,2}$ (1) $\cdot$ Priyanka deSouza ${ }^{1} \cdot$ Matthew Raifman $^{3}$
}

Received: 22 October 2020 / Revised: 12 December 2020 / Accepted: 14 December 2020 / Published online: 19 January 2021

(C) W. Montague Cobb-NMA Health Institute 2021

\begin{abstract}
Substantial health disparities exist across race/ethnicity in the USA, with Black Americans often most affected. The current COVID-19 pandemic is no different. While there have been ample studies describing racial disparities in COVID-19 outcomes, relatively few have established an empirical link between these disparities and structural racism. Such empirical analyses are critically important to help defuse "victim-blaming" narratives about why minority communities have been badly hit by COVID19. In this paper, we explore the empirical link between structural racism and disparities in county-level COVID-19 outcomes by county racial composition. Using negative binomial regression models, we examine how five measures of county-level residential segregation and racial disparities in socioeconomic outcomes as well as incarceration rates are associated with county-level COVID-19 outcomes. We find significant associations between higher levels of measured structural racism and higher rates of COVID-19 cases and deaths, even after adjusting for county-level population sociodemographic characteristics, measures of population health, access to healthcare, population density, and duration of the COVID-19 outbreak. One percentage point more Black residents predicted a $1.1 \%$ increase in county case rate. This association decreased to $0.4 \%$ when structural racism indicators were included in our model. Similarly, one percentage point more Black residents predicted a $1.8 \%$ increase in county death rates, which became non-significant after adjustment for structural racism. Our findings lend empirical support to the hypothesis that structural racism is an important driver of racial disparities in COVID-19 outcomes, and reinforce existing calls for action to address structural racism as a fundamental cause of health disparities.
\end{abstract}

Keywords Race $\cdot$ COVID-19 $\cdot$ Structural racism $\cdot$ Residential segregation, disparities

\section{Introduction}

In the USA, substantial and persistent disparities in health outcomes and healthcare access across race and ethnicity are well documented, particularly among non-Hispanic Black residents [1-3]. While studies highlighting these disparities are invaluable in drawing attention to this problem, an inherent danger of studying ethnic or racial categories is that doing so might reinforce the dominant interpretation of these categories

Shin Bin Tan

shinbin@mit.edu; shinbin@nus.edu.sg

1 Department of Urban Studies and Planning, Massachusetts Institute of Technology, Cambridge, MA, USA

2 Lee Kuan Yew School of Public Policy, National University of Singapore, Singapore, Singapore

3 Department of Environmental Health, Boston University School of Public Health, Boston, MA, USA as fundamentally distinct in terms of biology, culture, and behavior, even if unintended by the authors [4].

The current COVID-19 crisis is no exception. As evidence of COVID-19's disproportionate impact on minority communities emerged [5-7], so did problematic, "victim-blaming" narratives about why this might be so. Minority communities have been blamed for taking fewer precautions to avoid COVID-19 infection, for being more biologically susceptible to the virus, as well as for having more underlying health conditions which in turn have been attributed to poor habits, unhealthy lifestyles, and a biological propensity for disease $[8,9]$.

While much of the research detailing COVID-19 racial disparities does point to structural racism as the culprit, few studies have explicitly and empirically explored this link [8]. By structural racism, we refer to the totality of ways in which societies foster racial discrimination, whether through housing, education, employment, healthcare, and criminal justice [10], and which is likely to be a "fundamental cause" of health disparities [11]. The practice of reporting racial disparities in 
COVID-19 outcomes without drawing an explicit empirical line to structural racism might inadvertently reinforce unspoken yet persistent negative stereotypes of minority communities, and might undermine efforts to eliminate health inequities.

In this paper, we respond to calls for empirical analysis of the relationship between structural racism and COVID-19 racial disparities $[3,8]$ by examining if measures of structural racism, as manifested in housing, socioeconomic, and criminal justice systems, explain the variation in COVID-19 outcomes at the county level after controlling for demographic and socioeconomic (SES) COVID-19 risk factors. We focus primarily on Black Americans, a community which has experienced a long and well-documented history of exploitation and racial discrimination that has in turn manifested in the form of persistent health disparities and preventable deaths. We believe there is an urgent need to attend to Black Americans' experiences in order to stop this continual perpetuation of violence on Black bodies. At the same time, we carry out our analysis with an understanding and acknowledgement that other non-White minorities such as Native Americans and the Hispanic community have also experienced tremendous discrimination and violence over the years, and are currently facing similar burdens during this pandemic that should not be overlooked.

\section{Defining and Measuring Structural Racism}

Measuring "exposure" to racism is challenging, because there are multiple time and context-specific pathways through which racism harms health. While much research has focused on interpersonal discrimination as a psychosocial stressor and reported associations between individual-level, self-reported experiences of racial discrimination, and health outcomes $[12,13]$, scholars have recently started to quantify structural racism using indicators of economic injustices, social deprivations, and institutional exclusion [13, 14]. There is, however, no single "gold standard" operationalization of structural racism. A 2018 systematic review of methods to quantify exposure to structural racism found a range of measures across domains of housing and residential patterns, social institutions, political participation, criminal justice, socioeconomic status, workplace environments, and immigration. Several studies quantified structural racism by the existence of racist policies, such as redlining and racial profiling by immigration officials, while others estimated structural racism by measuring the racial gap in observed outcomes such as incarceration rates, higher education attainment, and employment [14].

While many dimensions of structural racism might explain COVID-19's disproportionate impact on Black communities, we focus on three key dimensions that have been more commonly hypothesized as causes of these COVID-19 disparities.
First, we examine residential segregation, which is defined as the degree to which two or more groups live separately from another in a geographic area. While some have attributed residential segregation to market-based sorting according to individual- and group-specific lifestyle preferences and socioeconomic status [15, 16], many others have also argued that such explanations cannot fully account for the extent and persistence of segregation experienced by Black communities. Scholars generally concur that in both historical and modern-day USA, governmental institutions, real estate, lending and construction industries created and maintained a dual housing market that restricted the residential mobility of Black Americans in a multitude of ways that included (but were not restricted to) discriminatory lending policies, zoning practices, and problematic low-income housing policies [16-19].

To date, segregation indices and evidence of historical redlining have received the lion's-share of attention within structural racism research, and have been linked to health disparities in a multitude of ways [14, 20-22]. Racial segregation overlaps with concentrated poverty and a lack of job opportunities [17, 23-25]. Those living in segregated areas tend to have access to fewer healthcare resources [26, 27] and poorer environmental quality [10, 28], as well as lower quality, more crowded housing conditions [17]. For these reasons, residential segregation has been widely hypothesized to be a driving factor in COVID-19 racial disparities [29, 30], and emerging studies have provided empirical evidence of the associations between residential segregation and COVID-19 cases [31].

While residential segregation is a critical dimension of structural racism in the USA, it does not represent other domains through which structural racism operates, such as workplaces, educational and social institutions, and judicial systems $[14,32]$. Scholars have thus called for more research using an expanded range of indicators beyond residential segregation and which examines the various facets of structural racism in tandem rather than in isolation $[14,22]$.

For our study, we examine structural racism that operates through economic injustice and social deprivation, evidenced from racial disparities in poverty rates and employment in professional, technical, or managerial jobs. Black-White disparities in socioeconomic outcomes have been attributed to various causes, including racial discrimination in hiring decisions [33, 34], spatial barriers to employment opportunities $[25,35,36]$ and educational opportunities [17, 37]. The latter two of which have roots in residential segregation, and the long tail of slavery and discriminatory Jim Crow laws [38, 39].

For COVID-19, this racial gap in socioeconomic outcomes could translate into racially patterned differences in access to health-preserving resources, such as healthcare, sanitizers and masks, and adequate shelter, as well as racially differentiated occupational and place-based risks [40, 41]. 
Finally, we examine structural racism within the criminal justice system, manifested as racial disparities in Black-White incarceration rates. These differences have been attributed to discriminatory policing, prosecuting, case processing, and sentencing practices $[10,42,43]$. Scholars have also highlighted how the lack of economic opportunities, access to quality schooling, and unstable living conditions in poor inner-city neighborhoods rendered young Black men susceptible to participating in criminal activity [42, 43].

Given the emerging link between higher rates of mass incarceration and COVID-19, scholars have also drawn links between the disproportionate rates of incarceration among Black communities and risks of COVID-19 [44-46].

\section{Materials and Methods}

\section{COVID-19 Outcome Measures}

Total COVID-19 cases and deaths per 1000 residents, as of September 25, 2020, are this study's outcomes of interest. We obtained county-level COVID-19 case and death data from January 22, 2020, to September 25, 2020, from USAFacts [47], a database that aggregates official COVID-19 statistics from the Centers for Disease Control and Prevention, stateand local-level public health agencies, and population estimates from the American Community Survey (ACS) 2014 2018. We also calculated the number of days since each county's first recorded case, as a control indicator of the progression of the outbreak within each county.

\section{Measures of Structural Racism}

\section{Structural Racism in Housing: Residential Segregation}

There have been many different measures of residential segregation developed over the years which can be categorized broadly into two major categories: spatial exposure/isolation, and spatial evenness/clustering. Spatial exposure refers to the extent members of one group encounter members of another group, while spatial isolation refers to the extent members of one group encounter members of their own group. Spatial evenness refers to the extent to which groups are similarly distributed, while its converse, spatial clustering, refers to how much groups are clustered together [48].

We utilize two measures to estimate these two distinct dimensions of segregation. The first is "Black-White Spatial Exposure" ( $\left.\tilde{\mathrm{P}}^{*}\right)$ score, which quantifies how likely Black residents are to encounter White residents within a county. The higher the $\tilde{\mathrm{P}}^{*}$ score, which ranges from 0 to 1 , the more spatially integrated Black residents are with White residents.

To measure spatial evenness/clustering, we utilize the "Spatial Information Theory Index" $(\tilde{H})$, which measures the extent to which individuals' local environments differ in population group composition [49]. Any deviation between an individual's localized population composition and the broader county-level composition would suggest clustering of different groups within the county. A higher $\tilde{\mathrm{H}}$ indicates more spatial segregation, while the maximum value of 1 indicates that all local environments consist of only one ethnicity/race, and is thus maximally segregated [48]. When calculating $\tilde{\mathrm{H}}$, we focus on the within-county spatial arrangement of four groups: Black, White, Hispanic, and all other non-White residents.

We calculate $\tilde{\mathrm{P}}^{*}$ and $\tilde{\mathrm{H}}$ using the ACS 2014-2018 5-year estimates for census tract population composition, to estimate county-level segregation patterns. Appendix A provides details of the calculations of these measures.

Racially Patterned Economic Injustice and Social Deprivation: Racial Disparities in Socioeconomic Outcomes

To measure the gap between socioeconomic attainment of Black residents compared to White residents, we use following county-wide indicators:

1. The ratio of the percent of Black residents living in poverty to the percent of White residents living in poverty;

2. The ratio of the percent of employed Black residents aged 16 and above who have professional, technical, or managerial employment, to the percent of employed White residents aged 16 and above who have professional, technical, or managerial employment.

These indicators are collated from diversitydatakids.org [50], which are based on American Community Surveys (ACS) 2013-2017 estimates.

\section{Structural Racism in the Criminal Justice System: Racial Disparities in Incarceration Rates}

We calculate the ratio of the Black residents' jail incarceration rate, to that of White residents', for each county, as of 2017. The data was compiled by the Vera Institute of Justice from the US Department of Justice Bureau of Justice Statistics (BJS), including The BJS Census of Jails, the Deaths in Custody Reporting Program (DCRP), and the Annual Survey of Jails [51]. Figure 1 maps the geographical distribution of each structural racism variable across continental USA.

\section{Other Model Covariates}

Our analyses control for county-level estimates of the proportion of Non-Hispanic Black residents, as well as proportion of Hispanic residents, from the 2014-2018 ACS.

Evidence suggests that older individuals aged 65 years and above and people with comorbidities are most at risk of death 
Spatial Exposure (B-W)

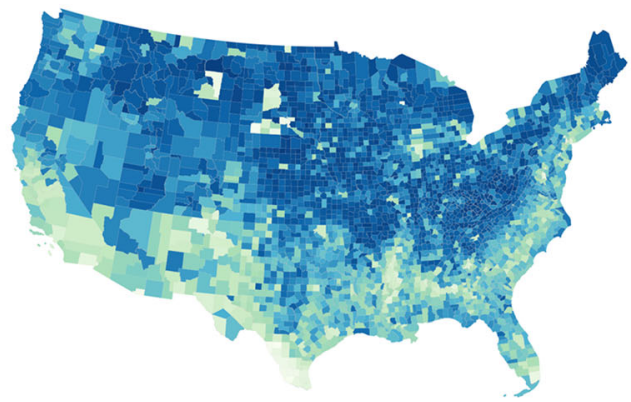

$\begin{array}{llllllllll}0.1 & 0.2 & 0.3 & 0.4 & 0.5 & 0.6 & 0.7 & 0.8 & 0.9 & 1.0\end{array}$

Ratio \% B:W Pop in Poverty

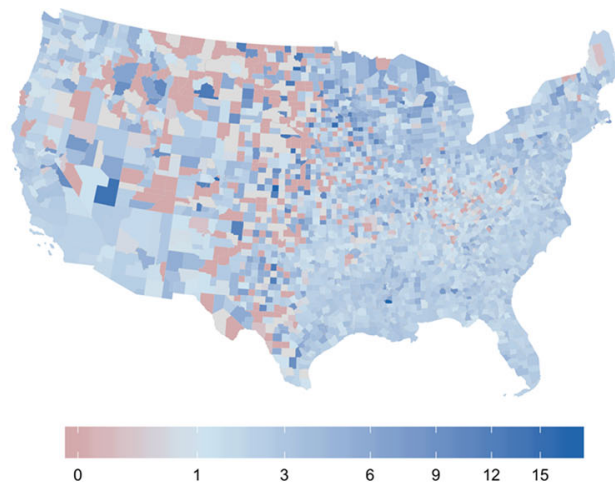

Spatial Information Theory

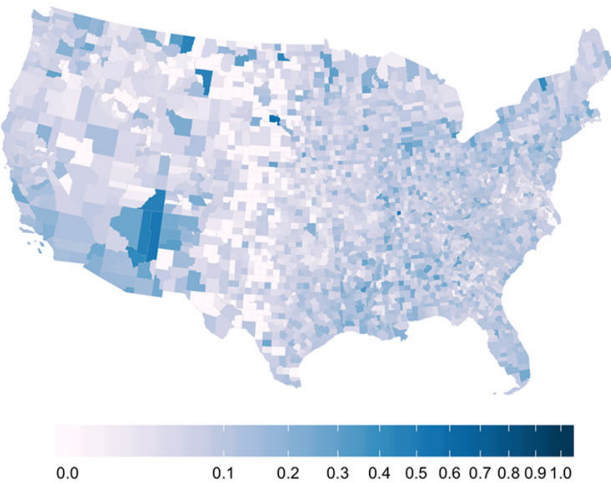

Ratio \% B:W Pop Managerial

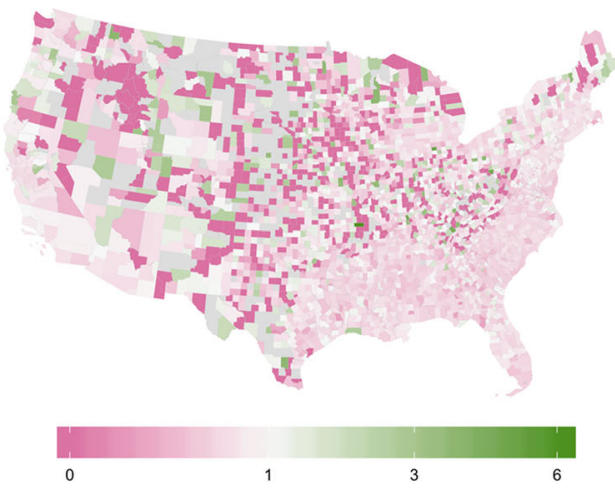

Ratio \% B:W Pop incarcerated

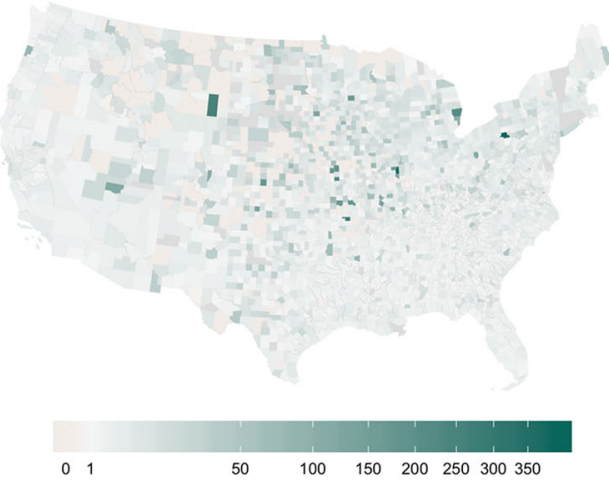

Fig. 1 Geographical distribution of structural racism measures

[52]. In order to account for the higher risk of death for older people, we include a variable of the percentage of people aged 65 years and older in a county. Additionally, we include the proportion of the population with underlying health risks in a county, drawing primarily from the County Health Rankings and Road Maps (CHRR), a collaboration between the Robert Wood Johnson Foundation and the University of Wisconsin Population Health Institute that aggregates various countylevel health data to produce rankings and reports on community health [53]. The first indicator from the CHRR that we include is the percentage of adults reporting fair or poor health (age-adjusted) as a rough proxy for underlying health conditions that might confound the relationship between county race/ethnic composition and COVID-19 outcomes. This indicator was drawn from the Behavioral Risk Factor Surveillance System (BRFSS) 2017.

We include a variable from the CHRR for the percent of population uninsured, to capture individuals' lack of access to healthcare. This variable was originally collated from the US Census Bureau's "Small Area Health Insurance Estimates," 2015.

Individuals of low socioeconomic status are also hypothesized to be particularly susceptible to COVID-19, for a myriad of reasons. They often lack access to basic health services, are 
more subject to miscommunication and misinformation about the disease [54], and can least afford protective measures such as the use of masks and sanitizers, and "sheltering in place" to avoid infection. In our analysis, we include the proportion of unemployed county residents (ACS 2014-2018) as a measure for socioeconomic status.

Besides county population composition, disparities in COVID-19 outcomes may also be driven by contextual factors. For instance, counties with a lower availability of healthcare resources are less likely to be able to cope with COVID-19, and may thus see worse outcomes. Thus, we include the number of physicians per 100 residents for each county, obtained from the CHRR, and which was originally collated from the Area Health Resource File/American Medical Association, 2017.

Additionally, as urban density is commonly assumed to contribute to the spread of COVID-19 [55], we include a categorical variable that splits counties into three tertiles of county population densities, calculated from 2014 to 2018 ACS.

\section{Analytic Sample and Variable Correlations}

Our models are based on an analytic population of 2599 counties, out of 3143 counties with COVID-19 case and death data. We drop 544 counties because of missing model covariates: data was missing from 184 counties about the ratio of Black: White rates of incarceration, 166 about the ratio of Black:White rates living in poverty; 330 about the ratio of Black:White population in managerial positions; and 147 counties about the number of primary care physicians per capita.

The five structural racism indicators and other model variables are weakly to moderately correlated: the structural racism variables have pairwise Pearson correlation coefficients of under 0.5 , and Pearson correlation coefficients of under 0.7 for all other variables. (See Fig. 2.)

\section{Statistical Methods}

We first explore the data by calculating the average number of COVID-19 cases and deaths for counties below and above the median value of each structural racism indicator, to examine if there are systematic differences in COVID-19 case and death rates between counties with higher vs lower levels of each measure of structural racism.

We then assess whether observed relationships might be confounded by the various county-level characteristic factors described above. To do so, we fit negative binomial models with a logarithmic link function, to model the relationship between county-level COVID-19 outcomes (number of cases and deaths) and our proposed structural racism measures, while controlling for the various covariates. The models include county population as an offset term, to model COVID19 case and death rates per capita. Exponentiated regression coefficients are presented as rate ratios of the two outcomes, and reported together with bootstrapped $95 \%$ confidence intervals (number of simulations $=500$ ).

States have different approaches to managing COVID-19, in terms of testing, social distancing orders, mandatory maskwearing, and other measures, all of which are likely to affect COVID-19 outcomes. We therefore include state-level random effects in both models to account for these differences.

Statistical significance is assessed using a $p<0.05$ threshold. All analyses were conducted in R. Statistical analysis was conducted using the "Ime4" package, 1.1-21 [56] while spatial segregation indices were calculated using "seg" 0.5-7 [57]. 2014-2018 ACS county-level population data was downloaded using the tidycensus $\mathrm{R}$ package.

\section{Results}

\section{Descriptive Statistics}

Figure 3 maps the number of cases and deaths per thousand population, for counties, while Table 1 summarizes the distribution of deaths, cases, structural racism indicators, and county characteristic parameters.

We find that counties with higher levels of structural racism, in terms of spatial residential segregation, Black/White disparities in poverty rates, and percentage in managerial positions, had higher average COVID-19 cases per capita and deaths per capita. The one exception is incarceration rates, where counties with a larger Black-White jail incarceration rate had fewer COVID-19 cases and deaths per population (Table 2).

\section{Regression Results}

In the models without the structural racism variables, each percentage point increase in Black population is associated with a statistically significant increase in case rate by a factor of 1.011 , or $1.1 \%$ (Table 3, Model 1) and an increase in death rates by $1.8 \%$ (Table 3 , Model 3 ) even after controlling for various county-level covariates.

After adding in the five structural racism variables, we see that this association drops to $0.4 \%$ for case rates, and the association between percentage Black and death rates is no longer statistically significant (Table 3, Models 2 and 4). There is a positive relationship between higher levels of racism, as measured by three of the structural racism variables, and worse COVID-19 outcomes. Specifically, higher Spatial Black-White Exposure ( $\left.\tilde{\mathrm{P}}^{*}\right)$, which indicates less residential segregation, is associated with lower case and death rates. Higher Spatial Information Theory Index $(\tilde{\mathrm{H}})$ values, which indicate less diversity of different racial/ethnic groups and thus more residential segregation, is associated with significantly higher case and death rates. 


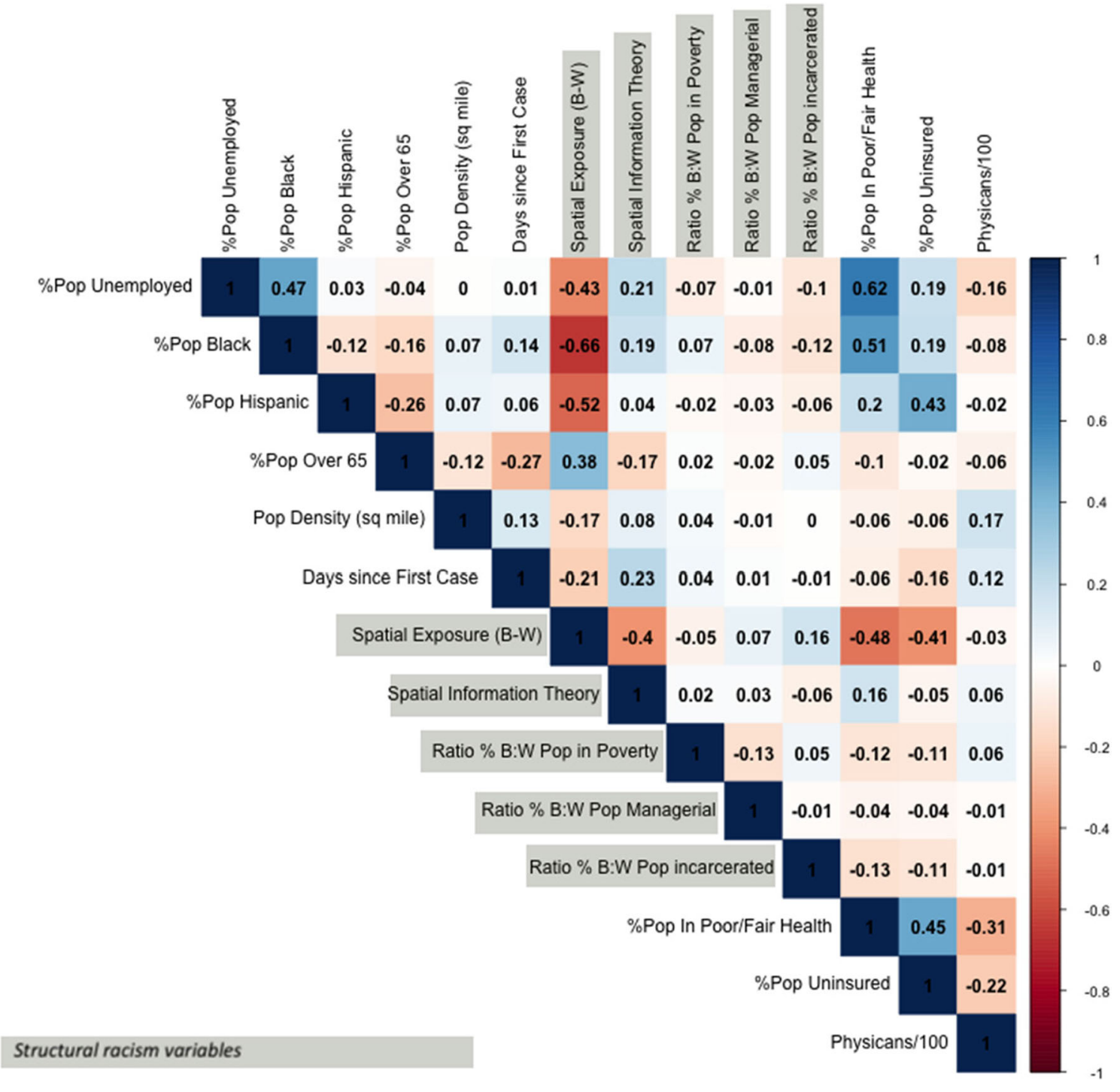

Fig. 2 Correlation between model variables
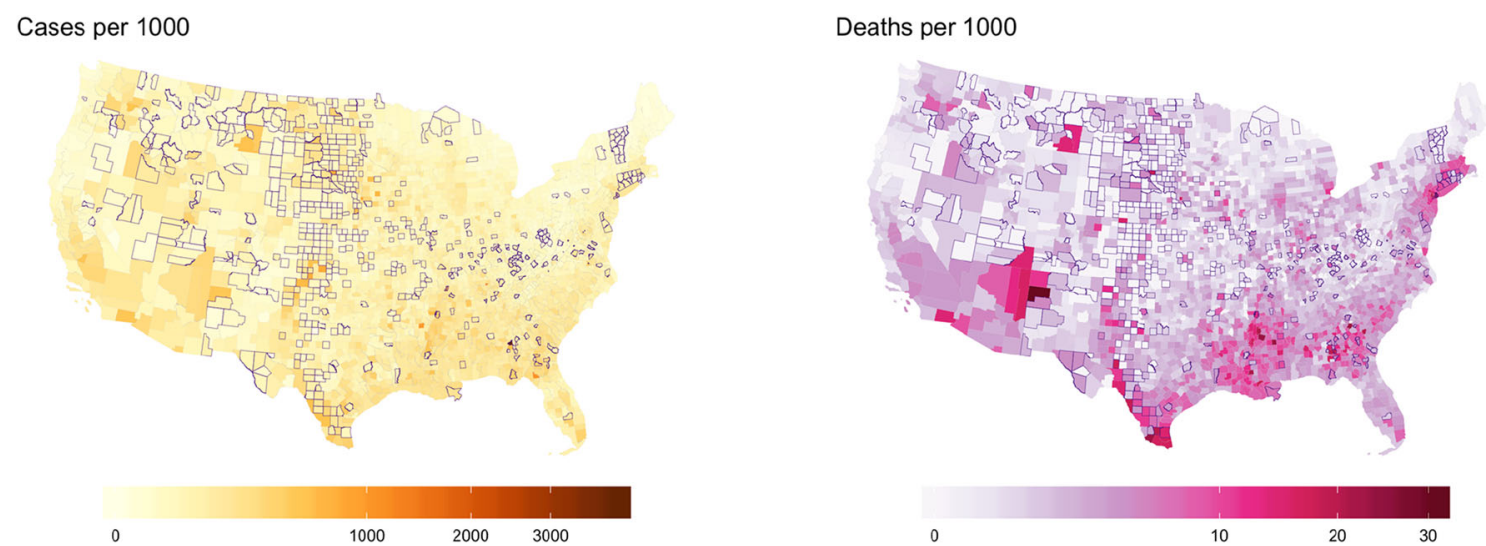

Fig. 3 Number of cases and number of deaths per thousand population, as of September 25, 2020. Counties outlined in gray were left out of the analysis, because of missing information. Note: Only continental states included in the maps 
Table 1 Summary statistics of COVID-19 outcomes, county covariates, and structural racism indicators

\begin{tabular}{lrlllll}
\hline Statistic & Mean & St. dev. & Min & $\begin{array}{l}25 \text { th } \\
\text { percentile }\end{array}$ & $\begin{array}{l}\text { 75th } \\
\text { percentile }\end{array}$ & Max \\
\hline Cases per 1000 & 120.3 & 101.9 & 0 & 49.2 & 165.1 & 1223.5 \\
Deaths per 1000 & 2.7 & 3.2 & 0 & 0.6 & 3.6 & 30.4 \\
\%Pop. Black & 10.2 & 15.1 & 0 & 0.9 & 12.3 & 87.4 \\
\%Pop. Hispanic & 9.2 & 13.1 & 0 & 2.2 & 9.7 & 99.1 \\
Spatial exposure (B-W) & 0.7 & 0.2 & 0.02 & 0.5 & 0.9 & 1.0 \\
Spatial information theory & 0.1 & 0.1 & 0 & 0.04 & 0.1 & 0.5 \\
Ratio of \% Black-White pop. in & 2.5 & 1.7 & 0 & 1.5 & 3.1 & 17.1 \\
$\quad$ poverty & 0.7 & 0.6 & 0 & 0.4 & 0.8 & 6.1 \\
Ratio of \% Black-White pop. in & & & & & & 398.7 \\
$\quad$ managerial positions & 7.2 & 18.1 & 0 & 2.1 & 6.5 & 25.8 \\
Ratio of \% Black-White pop. & & & & & 7.1 & 55.6 \\
$\quad$ incarcerated & 5.9 & 2.5 & 0 & 4.2 & 20.1 & 38.9 \\
\%Pop. unemployed & 17.9 & 4.3 & 6.4 & 15.2 & 33.7 \\
\%Pop. over 65 & 18.1 & 4.6 & 8.1 & 14.6 & 21 & 5.1 \\
\%Pop. in poor/fair health & 11.2 & 5 & 2.3 & 7.2 & 14.1 & $72,053.0$ \\
\%Pop. uninsured & 0.6 & 0.3 & 0 & 0.3 & 0.7 & 247 \\
Primary care physicians/100 & 270.3 & 1647.1 & 0.1 & 25.2 & 144.2 & 190 \\
Pop. density (sq. mile) & 180.8 & 19.8 & 1 & 177 & & \\
Days since first case & & & & & & \\
\hline
\end{tabular}

Higher ratios of Black: White percentage in poverty are associated with higher case rates, but not death rates. Employment-related and incarceration-related racial disparities are not statistically significantly associated with either case or death rates.

\section{Discussion}

Risk factors such as economic disadvantage and chronic health problems are routinely offered as explanations for COVID-19's disproportionate impact on Black communities. However, similar to Millet et al. [6], we find that even after controlling for various population compositional and ecological variables that might explain higher COVID-19 rates among Black communities, a higher county proportion of Black residents still remains significantly associated with higher case and death rates.

When we include county-level structural racism indicators into our regression models, the associations between the percentage of Black residents and COVID-19 case and death rate drop from a factor of 1.011 to 1.004 , and from 1.018 to nonsignificance respectively (Table 3 ). Our findings thus suggest that the racial disparities in county-level COVID-19 case and death rates are, in part, explained by variations in structural racism variables, specifically the ones measuring residential

Table 2 COVID-19 outcomes for the different ranges of structural racism

\begin{tabular}{|c|c|c|c|c|c|}
\hline \multirow[b]{2}{*}{ Structural racism variable } & \multirow[b]{2}{*}{$\begin{array}{l}\text { Variable } \\
\text { median value }\end{array}$} & \multicolumn{2}{|l|}{$\begin{array}{l}\text { Cases per } 1000 \\
\text { Mean }(95 \% \mathrm{CI})\end{array}$} & \multicolumn{2}{|l|}{$\begin{array}{l}\text { Deaths per } 1000 \\
\text { Mean }(95 \% \mathrm{CI})\end{array}$} \\
\hline & & $\begin{array}{l}\text { Counties with } \\
\text { lower structural } \\
\text { racism }\end{array}$ & $\begin{array}{l}\text { Counties with } \\
\text { higher structural } \\
\text { racism }\end{array}$ & $\begin{array}{l}\text { Counties with } \\
\text { lower structural } \\
\text { racism }\end{array}$ & $\begin{array}{l}\text { Counties with } \\
\text { higher structural } \\
\text { racism }\end{array}$ \\
\hline Spatial exposure (B-W) & 0.75 & $\begin{array}{l}75.29 \\
(71.72,78.85)\end{array}$ & $\begin{array}{l}165.29 \\
(159.23,171.35)\end{array}$ & $\begin{array}{l}1.31 \\
(1.22,1.39)\end{array}$ & $\begin{array}{l}4.04 \\
(3.84,4.24)\end{array}$ \\
\hline Spatial information theory & 0.07 & $\begin{array}{l}101.13 \\
(95.91,106.35)\end{array}$ & $\begin{array}{l}139.40 \\
(133.74,145.06)\end{array}$ & $\begin{array}{l}1.99 \\
(1.84,2.14)\end{array}$ & $\begin{array}{l}3.36 \\
(3.17,3.54)\end{array}$ \\
\hline Ratio of \% Black-White pop. in poverty & 2.23 & $\begin{array}{l}114.62 \\
(109.14,120.1)\end{array}$ & $\begin{array}{l}125.92 \\
(120.33,131.51)\end{array}$ & $\begin{array}{l}2.33 \\
(2.17,2.49)\end{array}$ & $\begin{array}{l}3.02 \\
(2.84,3.2)\end{array}$ \\
\hline Ratio of \% Black-White pop. in managerial positions & 0.6 & $\begin{array}{l}117.02 \\
(111.92,122.11)\end{array}$ & $\begin{array}{l}123.53 \\
(117.58,129.48)\end{array}$ & $\begin{array}{l}2.58 \\
(2.42,2.74)\end{array}$ & $\begin{array}{l}2.77 \\
(2.59,2.96)\end{array}$ \\
\hline Ratio of \% Black-White pop. incarcerated & 3.52 & $\begin{array}{l}137.04 \\
(130.83,143.24)\end{array}$ & $\begin{array}{l}103.52 \\
(98.9,108.14)\end{array}$ & $\begin{array}{l}2.92 \\
(2.74,3.09)\end{array}$ & $\begin{array}{l}2.43 \\
(2.26,2.6)\end{array}$ \\
\hline
\end{tabular}


Table 3 Rate ratios of county COVID-19 case and death rates

\begin{tabular}{|c|c|c|c|c|}
\hline & \multicolumn{2}{|c|}{$\begin{array}{l}\text { Cases Per } 1000 \text { Coef } \\
(95 \% \text { CI })\end{array}$} & \multicolumn{2}{|c|}{$\begin{array}{l}\text { Deaths Per } 1000 \text { Coef } \\
(95 \% \text { CI })\end{array}$} \\
\hline & Model 1 & Model 2 & Model 3 & Model 4 \\
\hline Intercept & $\begin{array}{l}0.006 * * * \\
(0.004,0.008)\end{array}$ & $\begin{array}{l}0.011 * * * \\
(0.008,0.017)\end{array}$ & $\begin{array}{l}0.00003 * * * \\
(0.00002,0.0001)\end{array}$ & $\begin{array}{l}0.0001 * * * \\
(0.0001,0.0002)\end{array}$ \\
\hline \%Pop. Black & $\begin{array}{l}1.011 * * * \\
(1.009,1.013)\end{array}$ & $\begin{array}{l}1.004 * * * \\
(1.001,1.008)\end{array}$ & $\begin{array}{l}1.018 * * * \\
(1.014,1.022)\end{array}$ & $\begin{array}{l}1.005 \\
(0.999,1.011)\end{array}$ \\
\hline \% Pop. Hispanic & $\begin{array}{l}1.013 * * * \\
(1.010,1.015)\end{array}$ & $\begin{array}{l}1.008 * * * \\
(1.005,1.012)\end{array}$ & $\begin{array}{l}1.013 * * * \\
(1.009,1.017)\end{array}$ & $\begin{array}{l}1.005 * \\
(1.000,1.011)\end{array}$ \\
\hline \multicolumn{5}{|l|}{ Structural racism variables } \\
\hline Spatial exposure (B-W) & & $\begin{array}{l}0.549 * * * \\
(0.419,0.750)\end{array}$ & & $\begin{array}{l}0.310^{* * *} \\
(0.192,0.499)\end{array}$ \\
\hline Spatial information theory & & $\begin{array}{l}2.272 * * * \\
(1.494,3.531)\end{array}$ & & $\begin{array}{l}3.562 * * * \\
(1.602,7.703)\end{array}$ \\
\hline Ratio of $\%$ Black-White pop. in poverty & & $\begin{array}{l}1.013 * * \\
(1.002,1.023)\end{array}$ & & $\begin{array}{l}1.015 \\
(0.994,1.036)\end{array}$ \\
\hline Ratio of $\%$ Black-White pop. in managerial positions & & $\begin{array}{l}0.974 * \\
(0.944,1.001)\end{array}$ & & $\begin{array}{l}0.994 \\
(0.936,1.051)\end{array}$ \\
\hline Ratio of $\%$ Black-White pop. incarcerated & & $\begin{array}{l}0.999 * \\
(0.998,1.000)\end{array}$ & & $\begin{array}{l}1.000 \\
(0.998,1.002)\end{array}$ \\
\hline \multicolumn{5}{|l|}{ County covariates } \\
\hline \% Pop. unemployed & $\begin{array}{l}0.989 * * \\
(0.978,0.999)\end{array}$ & $\begin{array}{l}0.983 * * * \\
(0.973,0.993)\end{array}$ & $\begin{array}{l}1.016 \\
(0.996,1.034)\end{array}$ & $\begin{array}{l}1.001 \\
(0.982,1.018)\end{array}$ \\
\hline \%Pop. over 65 & $\begin{array}{l}0.966 * * * \\
(0.961,0.971)\end{array}$ & $\begin{array}{l}0.970 * * * \\
(0.964,0.974)\end{array}$ & $\begin{array}{l}1.007 \\
(0.998,1.016)\end{array}$ & $\begin{array}{l}1.016^{* * *} \\
(1.006,1.027)\end{array}$ \\
\hline \%Pop. in poor/fair health & $\begin{array}{l}1.017 * * * \\
(1.008,1.026)\end{array}$ & $\begin{array}{l}1.016 * * * \\
(1.007,1.025)\end{array}$ & $\begin{array}{l}1.021 * * \\
(1.003,1.036)\end{array}$ & $\begin{array}{l}1.022 * * * \\
(1.006,1.039)\end{array}$ \\
\hline$\%$ Pop. uninsured & $\begin{array}{l}1.036 * * * \\
(1.027,1.045)\end{array}$ & $\begin{array}{l}1.025 * * * \\
(1.014,1.035)\end{array}$ & $\begin{array}{l}1.037 * * * \\
(1.020,1.052)\end{array}$ & $\begin{array}{l}1.017 * * \\
(0.999,1.033)\end{array}$ \\
\hline Primary care physicians/100 & $\begin{array}{l}1.002 \\
(0.944,1.056)\end{array}$ & $\begin{array}{l}0.964 \\
(0.908,1.023)\end{array}$ & $\begin{array}{l}1.054 \\
(0.939,1.188)\end{array}$ & $\begin{array}{l}0.957 \\
(0.861,1.055)\end{array}$ \\
\hline Pop. density (2nd tertile) & $\begin{array}{l}1.011 \\
(0.961,1.068)\end{array}$ & $\begin{array}{l}1.000 \\
(0.947,1.060)\end{array}$ & $\begin{array}{l}1.032 \\
(0.935,1.149)\end{array}$ & $\begin{array}{l}1.032 \\
(0.935,1.149)\end{array}$ \\
\hline Pop. density (3rd tertile) & $\begin{array}{l}1.032 \\
(0.965,1.107)\end{array}$ & $\begin{array}{l}0.978 \\
(0.906,1.042)\end{array}$ & $\begin{array}{l}1.081 \\
(0.966,1.221)\end{array}$ & $\begin{array}{l}1.003 \\
(0.893,1.128)\end{array}$ \\
\hline Days since first case & $\begin{array}{l}1.004 * * * \\
(1.003,1.005)\end{array}$ & $\begin{array}{l}1.003 * * * \\
(1.002,1.005)\end{array}$ & $\begin{array}{l}1.005 * * * \\
(1.003,1.008)\end{array}$ & $\begin{array}{l}1.004 * * * \\
(1.002,1.007)\end{array}$ \\
\hline Observations & 2599 & 2599 & 2599 & 2599 \\
\hline Log likelihood & $-18,384.75$ & $-18,336.68$ & -9523.95 & -9482.15 \\
\hline Akaike inf. crit. & $36,795.51$ & $36,709.36$ & $19,073.90$ & $19,000.29$ \\
\hline Bayesian inf. crit. & $36,871.72$ & $36,814.90$ & $19,150.12$ & $19,105.82$ \\
\hline
\end{tabular}

$* p<0.1 ; * * p<0.05 ; * * * p<0.01$

segregation and the Black-White poverty rate ratio. In other words, our findings lend empirical support to the hypothesis that structural racism is an important driver of COVID-19 racial disparities.
Scholars hypothesize that the causal mechanisms operating along the different dimensions of residential segregation are specific to outcome types and sociodemographic characteristics [58]. For instance, some theorize that isolation/exposure 
dimension might prove more conducive to the spread of infectious diseases [23], whereas clustering/evenness dimension might be more predictive of the degree of minority unemployment [59]. In the case of COVID-19, which is an infectious disease that disproportionately affects the socioeconomically vulnerable, it seems intuitive that both isolation/exposure $(\mathrm{P})$ and clustering/evenness $(\mathrm{H})$ dimensions of residential segregation might matter for COVID-19 outcomes-which is exactly what we find.

We find that higher ratios of Black:White population percentage in poverty are associated with higher case rates, but not death rates. This finding suggests racially differentiated access to resources might be linked to greater risks of initial exposure to COVID-19, perhaps because of the lack of sanitizers, masks, and shelter, but not necessarily more deaths after controlling for underlying comorbidities.

Occupation-related and incarceration-related structural racism variables are not statistically significantly associated with case or death rates, contrary to our initial hypothesis. It could be that structural racism in the criminal justice domain are relatively less consequential in determining susceptibility to COVID-19, compared to residential segregation and poverty rates. It could also be that these particular measures insufficiently capture the extent of structural racism within these two domains.

Even after controlling for the different structural racism indicators, the percentage of Black residents in a county is still significantly positively associated with COVID-19 cases per 1000 residents in a county. We interpret this finding as a sign that the variables we include in our analysis, while a useful starting point, do not comprehensively capture the structural forces that result in the serial marginalization of Black populations. Our results may thus underestimate the relationship between structural racism and COVID-19 outcomes, and that much more work is needed for a proper accounting of pathways between the two. We also find relatively low to moderate levels of correlations between our five structural racism variables, which suggest that each variable represents a quantitatively distinct aspect of structural racism. Collectively, these findings reinforce current calls for researchers to look beyond residential segregation indices, and to include other measures of structural racism.

\section{Limitations}

Our conclusions are restricted at the county level, as we do not have access to individual-level COVID-19 data. Extrapolating our findings to conclusions about individual-level COVID-19 risk would be subject to problems of ecological fallacy ([60, 61]). Nevertheless, taking a county-level approach to analyzing disparities in COVID-19 is important. First, county-level data on cases/deaths are currently the best real-time source of COVID-19 information, and allows for more timely analyses that could help guide the prioritization of resources and interventions to areas most at risk. Second, as we have shown through our exploratory analyses, there are likely to be structural, ecological factors exacerbating the spread of COVID19 , beyond "compositional" population factors which aggregate individual-level risks, and should be given due attention.

However, without comprehensive individual-level COVID-19 case/death data, it is impossible to unpack how much of the observed disparities are due to compositional population "sum of parts," or contextual effects like residential segregation, or unequal job markets (Subramanian et al. 2009). Our study thus reinforces the call for more individuallevel race/ethnicity data on testing, cases, and deaths, and for more multilevel studies on how individuals' outcomes interact with structural parameters such as the ones we explore.

Another limitation of our study is its reliance on official COVID-19 case and death data. Evidence suggests substantial under-reporting of COVID-19 outcomes. For instance, Vaid et al. [62] estimate that, as of April 2020, the number of real infections in the USA could be between 1.5 to 2 times the number of reported infections. Additionally, a study found that working-class populations in lower-SES areas were less likely to receive tests and more likely to be positive when tested compared to those in White neighborhoods [63]. Collectively, these findings suggest that studies based on official COVID-19 data, including ours, may severely underestimate COVID-19's impact on minorities and the poor.

Finally, these indicators of structural racism are broad estimates based on readily available data and guided by existing literature. They may not be specific enough to capture the actual differences between Black and White populations that matter particularly for COVID-19. Future studies would benefit from exploring alternative measures of structural racism, such as Black:White differences in essential worker status.

\section{Conclusion}

We find that counties with higher levels of structural racism were more severely impacted by the virus, which supports our argument that researchers should not rely on the usual basket of individual behavioral or biological risk factors to explain health disparities. Rather, more work is needed to interrogate the fundamental, structural causes driving these inequities. This study also reinforces calls for more resources and remediatory efforts to be channeled to communities that have been, and are being, hurt by structural racism. Furthermore, even after the COVID-19 pandemic has subsided, longer-term efforts to reform government institutions and policies that perpetuate residential segregation and economic disparities have to continue, to avoid a repeat of the current devastation. Urgent and sustained action is needed to correct the course of this deadly affliction. 
Supplementary Information The online version contains supplementary material available at https://doi.org/10.1007/s40615-020-00948-8.

Acknowledgments The authors would like to thank Mariana Arcaya and Patrick Kinney for providing invaluable feedback that helped us improve our paper.

Funding Matthew Raifman's work was supported by training grant number 5T32ES014562-13 from the NIH National Institute of Environmental Health Sciences.

Data Availability To be made available upon request from corresponding author.

\section{Compliance with Ethical Standards}

Conflict of Interest The authors declare that they have no conflicts of interest.

Code Availability To be made available upon request from corresponding author.

\section{References}

1. Barr DA. Health disparities in the United States: social class, race, ethnicity, and health. JHU Press; 2014.

2. Williams DR. Miles to go before we sleep: racial inequities in health. J Health Soc Behav. Sage Publications Sage CA: Los Angeles, CA; 2012;53:279-295.

3. Laurencin CT, McClinton A. The COVID-19 pandemic: a call to action to identify and address racial and ethnic disparities. J Racial Ethn Health Disparities. 2020:1-5.

4. Bradby H. Race, ethnicity and health: the costs and benefits of conceptualising racism and ethnicity. Soc Sci Med. 2012;75:955-8.

5. Bassett M, Chen JT, Krieger N. The unequal toll of COVID-19 mortality by age in the United States: quantifying racial/ethnic disparities. Harvard Center for Population and Development Studies; 2020.

6. Millett GA, Jones AT, Benkeser D, Baral S, Mercer L, Beyrer C, et al. Assessing differential impacts of COVID-19 on black communities. Ann Epidemiol. 2020;47:37-44.

7. Raifman M, Raifman J. Disparities in the population at risk of severe illness from COVID-19 by race/ethnicity and income. Am J Prev Med. Elsevier; 2020

8. Boyd RW, Lindo EG, Weeks LD, McLemore MR. On racism: a new standard for publishing on racial health inequities | Health Affairs [Internet]. 2020 [cited 2020 Jul 30]. Available from: https://www.healthaffairs.org/do/10.1377/hblog20200630.939347/ full/

9. Chowkwanyun M, Reed AL. Racial health disparities and Covid19 - caution and context. N Engl J med. Massachusetts Medical Society; 2020;383:201-203.

10. Bailey ZD, Krieger N, Agénor M, Graves J, Linos N, Bassett MT. Structural racism and health inequities in the USA: evidence and interventions. The Lancet Elsevier. 2017;389:1453-63.

11. Phelan JC, Link BG. Is racism a fundamental cause of inequalities in health? Annu Rev Sociol Annual Reviews. 2015;41:311-30.

12. Kirkinis K, Pieterse AL, Martin C, Agiliga A, Brownell A. Racism, racial discrimination, and trauma: a systematic review of the social science literature. Ethn Health. Taylor \& Francis; 2018;0:1-21.

13. Krieger N. Discrimination and health inequities. Int J Health Serv. 2014;44:643-710.
14. Groos M, Wallace M, Hardeman R, Theall KP. Measuring inequity: a systematic review of methods used to quantify structural racism 2018;11:16.

15. Clark WAV. Residential preferences and neighborhood racial segregation: a test of the Schelling segregation model. Demography. 1991;28:1-19.

16. Charles CZ. The dynamics of racial residential segregation. Annu Rev Sociol. 2003;29:167-207.

17. Williams DR, Collins C. Racial residential segregation: a fundamental cause of racial disparities in health. Public Health Rep. 2001;116:404-16.

18. Rothstein R. The color of law: a forgotten history of how our government segregated America. New York: Liveright Publishing; 2017.

19. Abramovitz M, Smith RJ. The Persistence of Residential Segregation by Race, 1940 to 2010: The role of federal housing policy. Fam Soc 2020;1044389420923469.

20. Dougherty GB, Golden SH, Gross AL, Colantuoni E, Dean LT. Measuring structural racism and its association with BMI. Am J Prev Med. 2020;59:530-7.

21. Massey DS, Denton NA. American apartheid: segregation and the making of the underclass. Cambridge: Harvard University Press; 1993.

22. Riley AR. Neighborhood disadvantage, residential segregation, and beyond-lessons for studying structural racism and health. J Racial Ethn Health Disparities. 2018;5:357-65.

23. Acevedo-Garcia D, Osypuk TL. Invited commentary: residential segregation and health - the complexity of modeling separate social contexts. Am J Epidemiol. 2008;168:1255-8.

24. Huie SAB. The components of density and the dimensions of residential segregation. Popul Res Policy Rev Springer; 2000;19:505524.

25. Squires GD, Kubrin CE. Privileged places: race, uneven development and the geography of opportunity in urban America. Urban Stud. Sage Publications Sage UK: London, England; 2005;42:4768 .

26. Anderson KF. Racial/ethnic residential segregation, the distribution of physician's offices and access to health care: the case of Houston, Texas. Soc Sci. 2018;7(8):119.

27. Dai D. Black residential segregation, disparities in spatial access to health care facilities, and late-stage breast cancer diagnosis in metropolitan Detroit. Health Place. 2010;16:1038-52.

28. Pulido L. Rethinking environmental racism: White privilege and urban development in Southern California. Ann Assoc Am Geogr Taylor \& Francis. 2000;90:12-40.

29. Barber S, Headen I, Branch B, Tabb LT, Yadeta K. COVID-19 in context: racism, segregation and racial inequities in Philadelphia. Drexel University Urban Health Collaborative. 2020. Available from: https://drexel.edu/uhc/resources/briefs/Covid-19\%20in\% 20Context/. Accessed 30 Sep 2020.

30. Egede LE, Walker RJ. Structural racism, social risk factors, and Covid-19 - a dangerous convergence for Black Americans. N Engl J Med. 2020;383(12):e77.

31. Yang T-C, Choi SE, Sun F. COVID-19 cases in US counties: roles of racial/ethnic density and residential segregation. Ethn Health Taylor \& Francis; 2020;0:1-11.

32. Chambers BD, Erausquin JT, Tanner AE, Nichols TR, Brown-Jeffy $\mathrm{S}$. Testing the association between traditional and novel indicators of county-level structural racism and birth outcomes among Black and White women. J Racial Ethn Health Disparities. 2018;5:96677.

33. Pager D, Shepherd H. The sociology of discrimination: racial discrimination in employment, housing, credit, and consumer markets. Annu Rev Sociol. 2008;34:181-209. 
34. Gaddis SM. Discrimination in the credential society: an audit study of race and college selectivity in the labor market. Soc Forces. 2015;93:1451-79.

35. Kain JF. The spatial mismatch hypothesis: three decades later. Hous Policy Debate. 1992;3:371-460.

36. Blumenberg E, Manville M. Beyond the spatial mismatch: welfare recipients and transportation policy. J Plan Lit. 2004;19:182-205.

37. Rothstein R. The racial achievement gap, segregated schools, and segregated neighborhoods: a constitutional insult. Race Soc Probl. 2015;7:21-30.

38. O'Connell HA. The impact of slavery on racial inequality in poverty in the contemporary U.S. south. Soc Forces. 2012;90:713-34.

39. Bertocchi G, Dimico A. Slavery, education, and inequality. Eur Econ Rev. 2014;70:197-209.

40. Bryan B. Homeownership experiences following criminal justice contact. Cityscape US Department of Housing and Urban Development. 2020;22:103-46.

41. Rollston R, Galea S. COVID-19 and the social determinants of health. Am J Health Promot SAGE Publications Inc. 2020;34: 687-9.

42. Pettit B, Western B. Mass imprisonment and the life course: race and class inequality in U.S. incarceration. Am Sociol Rev. 2004;69: 151-69.

43. Travis J, National Research Council, editors. The growth of incarceration in the United States: exploring causes and consequences. Washington, DC: The National Academies Press; 2014.

44. Escobar G, Taheri S. Incarceration weakens a community's immune system: mass incarceration and COVID-19 cases in Milwaukee. Measures for Justice; 2020.

45. Laurencin CT, Walker JM. A pandemic on a pandemic: racism and COVID-19 in blacks. Cell Syst. 2020;11:9-10.

46. Nowotny K, Bailey Z, Omori M, Brinkley-Rubinstein L. COVID19 exposes need for progressive criminal justice reform. Am J Public Health. American Public Health Association. 2020;110: 967-8.

47. USAFacts. US Coronavirus Cases and Deaths [Internet]. USAFacts.org. 2020 [cited 2020 Sep 25]. Available from: /visualizations/coronavirus-covid-19-spread-map

48. Reardon SF, O'Sullivan D. Measures of spatial segregation. Sociol Methodol Wiley Online Library. 2004;34:121-62.

49. Iceland J. Beyond Black and White: metropolitan residential segregation in multi-ethnic America. Soc Sci Res. 2004;33:248-71.
50. diversitydatakids.org. Datasets - CKAN [Internet]. Divers. Data Diverse Equitable Future. [cited 2020 Aug 14]. Available from: http://data.diversitydatakids.org/dataset

51. Vera Institute. vera-institute/incarceration-trends [Internet]. Vera Institute of Justice; 2020 [cited 2020 Aug 25]. Available from: $\mathrm{https}$ //github.com/vera-institute/incarceration-trends

52. CDC. Coronavirus Disease 2019 (COVID-19) in the U.S. [Internet]. Cent. Dis. Control Prev. 2020 [cited 2020 Jun 9]. Available from: https://www.cdc.gov/coronavirus/2019-ncov/ cases-updates/cases-in-us.html

53. County Health Rankings. 2019 California Report [Internet]. Cty. Health Rank. Roadmaps. [cited 2019 Nov 8]. Available from: https://www.countyhealthrankings.org/reports/state-reports/2019california-report

54. Ahmed F, Ahmed N, Pissarides C, Stiglitz J. Why inequality could spread COVID-19. Lancet Public Health. Elsevier; 2020;5:e240.

55. Rosenthal BM. Density is New York City's big 'enemy'in the coronavirus fight. N Y Times 2020

56. Bates D, Mächler M, Bolker B, Walker S. Fitting linear mixedeffects models using lme4. ArXiv Prepr ArXiv14065823. 2014

57. Hong S-Y, O'Sullivan D. seg: a set of tools for measuring spatial segregation [Internet]. 2014 [cited 2017 May 29]. Available from: https:/cran.r-project.org/web/packages/seg/index.html

58. Kramer MR, Hogue CR. Is segregation bad for your health? Epidemiol Rev Oxford University Press. 2009;31:178-94.

59. Dickerson NT. Black employment, segregation, and the social organization of metropolitan labor markets. Econ Geogr Routledge. 2007;83:283-307.

60. Robinson WS. Ecological correlations and the behavior of individuals. Int J Epidemiol. Oxford Academic. 2009;38:337-41.

61. Subramanian SV, Jones K, Kaddour A, Krieger N. Revisiting Robinson: the perils of individualistic and ecologic fallacy. Int J Epidemiol Oxford Academic. 2009;38:342-60.

62. Vaid S, Cakan C, Bhandari M. Using machine learning to estimate unobserved COVID-19 infections in North America. J Bone Joint Surg Am [Internet]. 2020 [cited 2020 Oct 5]; Available from: https://www.ncbi.nlm.nih.gov/pmc/articles/PMC7396213/

63. Lieberman-Cribbin W, Tuminello S, Flores RM, Taioli E. Disparities in COVID-19 testing and positivity in New York City. Am J Prev Med. 2020;59:326-32.

Publisher's Note Springer Nature remains neutral with regard to jurisdictional claims in published maps and institutional affiliations. 